\title{
Placental Malaria: A New Insight into the Pathophysiology
}

\author{
Lalita Sharma and Geeta Shukla* \\ Department of Microbiology, Panjab University, Chandigarh, India
}

Malaria in pregnancy poses a great health risk to mother and her fetus and results into complications, such as abortion, still birth, intra uterine growth retardation, and low birth weight. The heavy infiltration of Plasmodium falciparum-infected RBCs in the intervillous spaces of placenta seems to be responsible for all the complications observed. Infected RBCs in the placenta cause an inflammatory environment with increase in inflammatory cells and cytokines which is deleterious to the placenta. Increased inflammatory responses in the infected placenta result into oxidative stress that in turn causes oxidative stress-induced placental cell death. Moreover, heat shock proteins that are produced in high concentration in stressed cells to combat the stress have been reported in fewer concentrations in malaria-infected placenta. Pathologies associated with placental malaria seems to be the effect of a change in immune status from antibody-mediated immune response to cell-mediated immune response resulting into excess inflammation, oxidative stress, apoptosis, and decreased heat shock protein expression. However, we also need to study other aspects of pathologies so that better drugs can be designed with new molecular targets.

Keywords: malaria, placenta, pregnancy, low birth weight, intra uterine growth retardation

\section{INTRODUCTION}

Malaria has been the most devastating infectious parasitic disease of human kind for centuries. In 2015 , an estimated 438,000 malaria deaths around the world have been reported, of which approximately $69 \%(306,000)$ were children under 5 years of age. Of all malaria deaths, $90 \%$ were reported from African regions and rest were from South-East Asia region and the Eastern Mediterranean region (1). Malaria causes a very high risk to the pregnant woman and her fetus/new born. In malaria endemic areas, it is estimated that at least $25 \%$ of pregnant women are infected with malaria, which attribute to more than $20 \%$ of all maternal deaths. Malaria accounts for over 10,000 maternal and 200,000 neonatal deaths per year globally (2). Malarial infection in pregnant women results into clinical complications, such as anemia, pulmonary edema, hypoglycemia, cerebral malaria, puerperal sepsis, and some time death too. Consequences of maternal malaria in fetus are abortion, still birth, intra uterine growth retardation (IUGR), premature delivery, and low birth weight (LBW) $(3,4)$. LBW of the infant has been suspected for poor cognitive and neurosensory development of the child (5-7). WHO recommends that in areas of high malaria transmission, people should be provided with insecticide-treated mosquito nets and intermittent preventive treatment (IPT) with sulphadoxine-pyrimethamine should be given as a part of antenatal care. Although, artemisininbased combination therapies are highly effective against $P$. falciparum infection, but its use has not been recommended during pregnancy (8). Placenta, which is the interface between mother and fetus, plays important role in successful pregnancy outcome and growth of the fetus that is critically dependent on the placenta. This review summarizes all the pathophysiological processes occurring 
in the placenta due to malarial infection. The review will give a better insight into understanding placental malaria and help researchers to develop new drug targets.

\section{PLACENTAL MALARIA}

Malarial infection in placenta is characterized by sequestration of Plasmodium falciparum-infected erythrocytes and infiltration of immune cells within the intervillous spaces of the placenta. The placenta turns black due to deposition of the malarial pigment. The parasite densities are much higher in the placenta compared to peripheral blood (9-11). The thickening of placental basement membrane, perivillous fibrinoid deposits, and syncytial knotting results into altered exchange system between mother and fetus. The placental insufficiency to provide nutrients to the fetus causes IUGR $(12,13)$. The enhanced susceptibility to infections during pregnancy results into high parasitemia and heavy infiltration of parasite-infected RBCs (iRBC) in placental vasculature, a privilege site where the parasite can avoid maternal immune response (14-16). Furthermore, it has been observed that woman who is pregnant for the first time (primigravidae) is more susceptible to malarial infection than woman who has conceived for second or third time (multigravidae). This resistance to the malarial infection in multigravidae is due to the development of placental parasite-specific immunity in second and third pregnancies (17-19).

The severities of malarial infection in pregnant women also depend on prevalence of the infection in a particular community or area. In malaria endemic areas, women with their first pregnancy show more susceptibility to the infection and $20-40 \%$ babies born have a LBW. However, multigravidae women develop immunity to placenta-specific $P$. falciparum and are less susceptible to the infection. Contrary to malaria endemic areas, in areas with low malaria incidence, primigravidae and multigravidae are equally susceptible. The more complications of placental malaria in primigravidae are due to the absence of placental parasite-specific immunity which develop in subsequent pregnancies (19-21).

\section{MOLECULAR BASIS OF PLACENTAL MALARIA}

The typical and important characteristic of $P$. falciparum-infected erythrocytes is to get attach to vascular endothelium and then sequester to different organs. The erythrocytes, infected with $P$. falciparum express parasite-specific ligands that bind to the receptors on vascular endothelial cells and are responsible for sequestration of infected erythrocytes to organs. The receptors that have been observed on the surface of $P$. falciparum-infected erythrocytes include $P$. falciparum erythrocyte membrane protein 1, 2, and 3 (Pf EMP 1, 2, and 3), histidine-rich protein I and II, sequestrin, rosettins and ring-infected erythrocyte membrane surface antigen (Pf 155/RESA). Ligands to the receptors include intercellular adhesion molecule 1, vascular cell adhesion molecule-1, chondroitin sulfate A (CSA), CD36, TSP, and endothelial leukocyte adhesion molecule-1 (22-24).
Plasmodium falciparum isolates from placenta have been found to express var2csa genes that code for Pf EMP1. The Pf EMP1 encoded by var2csa bind to CSA present in placenta and responsible for sequestration. Var2csa gene is over expressed by P. falciparum isolates from the placenta $(20,25)$. Interestingly, $P$. falciparum parasites isolated from placenta do not bind to CD36 that is opposite in nature to $P$. falciparum isolates from non-pregnant women $(23,26)$. Thus, PfEMP1 proteins encoded by var2csa could prove as potential candidates for vaccine targets (27). Placental isolates of malaria parasite show different degrees of abilities to bind to CSA that may describe the complications of malaria in primigravidae where var2csa show more expression and more binding to $\operatorname{CSA}(28,29)$.

\section{IMMUNOLOGY OF PLACENTAL MALARIA}

The altered physiology and immunity during pregnancy and ability of $P$. falciparum-infected erythrocytes to sequester to various organs are all together responsible for severe malaria in pregnant women especially in first pregnancy and associated IUGR and LBWs in infants (30). The increased concentration of cortisol, during pregnancy makes women more susceptible to malaria by directly inhibiting NK cell activity against $P$. falciparum-infected erythrocytes. In pregnant women cell-mediated immunity (CMI) is halted which is required to support the development of placenta and the fetus. But this halt in CMI make pregnant women more susceptible to intracellular pathogens. However, in malaria-infected pregnant women, an increase in CMI has been observed in the local placental environment. Elevated levels of pro-inflammatory cytokines, such as IFN- $\gamma$, IL- 2 , and TNF- $\alpha$, in the placenta of malaria-infected women especially in primigravidae account for the observed placental pathology and adverse pregnancy outcomes (31-33). However, IFN- $\gamma$ levels have also been found elevated in placenta of multigravidae and this scenario can be explained on the bases of development of placental parasite-specific immunity in second or subsequent pregnancies which neutralizes the adverse effect of IFN- $\gamma(34-36)$.

The levels of chemokines have been observed elevated in the placental intervillous spaces, which correlate with increased monocyte density, parasite density, and malaria pigments in the placenta. Maternal macrophages are the predominant source of chemokines in the placenta, but fetus cells can also contribute. The chemokines help to recruit macrophages, cytotoxic T cells, $\mathrm{B}$ cells, and granulocytes in the placenta and contribute to the pathologies of placental malaria. There is excessive sequestration of iRBC and leukocytes in the intervillous spaces of placenta and formation of perivillous fibrin clot during malarial infection, which interfere blood flow across the placenta thus, nutrients to the fetus $(37,38)$. The low levels of HDL-C and increased TG levels in plasma of malaria-infected pregnant women may also be one of the factors for adverse pregnancy outcomes in malaria (39). Placental pathology in malaria is caused by expression of unique Pf EMP1 protein on iRBC which helps the parasite to sequester into the placenta. Women, who have malaria during pregnancy, develop Pf EMP1-specific antibodies and these antibodies protect women from malaria in subsequent pregnancies (40-43). 


\section{REACTIVE OXYGEN SPECIES (ROS) AND PLACENTAL MALARIA}

A balance between ROS and antioxidants is required for normal physiology in animals and any alteration that results in overabundance of ROS cause stress and damage to cells, tissues, and organs $(44,45)$. Several studies have documented increased oxidative stress during pregnancy, affecting the multiple physiological processes, i.e., oocyte maturation and fertilization, embryo development, initiation of preterm labor, and normal parturition (46-48). The antigenic stimulation due to malarial infection activates the macrophages and activated macrophages release ROS to destroy the intracellular parasite $(49,50)$. ROS are also produced by the Plasmodium parasite for degradation of hemoglobin $(51,52)$. To some extent, ROS are beneficial; by helping the patient to fight intra cellular parasite. But massive production of ROS by infiltered immune cells in the placenta results into damage of vascular lining and placental cells (53-55). A high rate of lipidperoxidation has been detected in the placenta of mouse infected with $P$. berghei where lipidperoxidation increased as the infection progressed. The same study also reported low catalase activity and low levels of SOD and GSH in the placenta and suggested that it might be responsible for high lipidperoxidation in the placenta (56-58). However, there are many other studies that suggest that reduced antioxidant levels are not responsible for oxidative stress in the placenta in malarial infection (59). Moreover, ROS generation by immune cells and infected erythrocytes also add to the oxidative stress in Plasmodium parasite-infected placenta. The increase in lipid peroxidation in the placenta of malaria-infected pregnant women could be responsible for increase in the serum triglycerides, cholesterol, and low density lipoproteins in malariapositive primigravidae (60). In cerebral malaria, ROS generation by monocytes and neutrophils at blood-brain barrier has been found to be responsible for damage to vascular cell lining and related complications (61-63). Thus, it seems that infiltration of $P$. falciparum-infected erythrocytes and immune cells to intervillous spaces of placenta results into production of ROS, increased TNF- $\alpha$ concentration and oxidative stress that contribute to placental pathology and associated clinical complications.

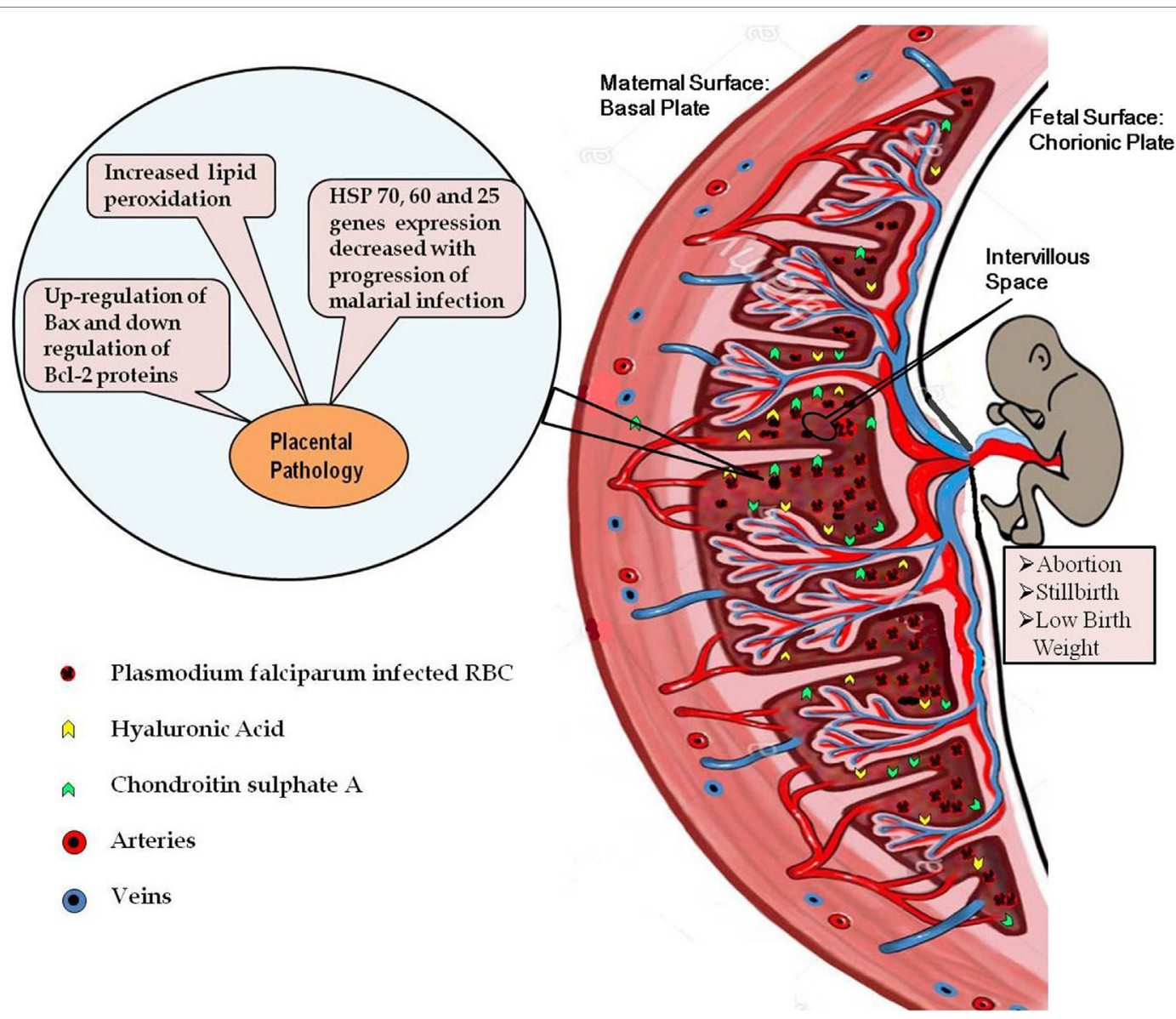

FIGURE 1 | Diagrammatic representation of the placental malaria and implications. Malarial infection during pregnancy results into infiltration of the parasite-infected RBCs to the intervillous space of placenta resulting into exacerbated inflammatory response. High inflammation causes oxidative stress-induced apoptotic cell death in the placenta. Decreased expressions of the heat shock protein genes in the infected placenta further contribute to the placental pathology. All these pathological alterations in the placenta contribute to the poor pregnancy outcomes associated with malarial infection. 


\section{APOPTOSIS AND PLACENTAL MALARIA}

Apoptosis is a programmed cell death which helps in maintaining homeostasis in the body. Impaired regulation of apoptosis has been found to be responsible for etiology of many diseases, e.g., cancer and autoimmune diseases $(64,65)$. On the other side, excessive death of cells due to apoptosis has been associated with neurodegenerative diseases and tissue damage in many diseases (66-68). A recent study has reported extensive cell death in the placenta of $P$. berghei-infected mice that have been linked to oxidative stress-induced apoptosis in the placenta (56). From the study, it is quite evident that oxidative stress and apoptosis are the two main reasons for observed placental pathology and related adverse effects in malaria-infected women and infants. However, a study has shown the effectiveness of sulphadoxine-pyrimethamine, the drug used for IPT in pregnancy and chloroquine in reducing pathologies of placenta induced by oxidative stress and apoptosis (69).

\section{HEAT SHOCK PROTEINS (HSPS) AND PLACENTAL MALARIA}

Heat shock proteins as suggested by their name are produced by cells in large quantities after a shock or a stress signal. These proteins help cells to recover from an injury or a shock (70). A wide range of HSPs have been observed throughout the pregnancy and found to be important for normal morphology and physiology of the placenta (71-73). HSPs are among the earliest proteins produced during zygote formation and are important for development of the embryo (74-76). In the last decade, there have been many articles stating the importance of HSPs in defense mechanisms against infectious as well as non-infectious diseases $(77,78)$. The role of HSPs in inhibition of apoptosis has been documented and found to be associated with cancer development. Many mechanisms of apoptosis inhibition have been reported, such as binding of HSP 90 to caspase-3 and HSP 60 to Bax and Bak proteins (79-81). However, Hsp 70 interferes with binding of Apaf-1 to procaspase-9 $(82,83)$. HSP 25 is also known for its antiapoptotic properties and plays important role in embryonic development $(84,85)$.

Malarial infection during pregnancy has been reported to cause HSPs response in placenta especially HSP 90, 70, 60, and 25 were detected at high levels in the placenta of mouse model of malaria infection. However, the levels of HSPs 70, 60, and 25 in the placenta decreased with progression of malarial infection. On the other hand, HSP 90 response increased gradually with

\section{REFERENCES}

1. WHO. World Malaria Report (2015). Available from: http://www.who.int/ malaria/publications/world-malaria-report-2015/report/en/

2. Schantz-Dunn J, Nour NM. Malaria and pregnancy: a global health perspective. Rev Obstet Gynecol (2009) 2(3):186-92.

3. Menendez C, Ordi J, Ismail MR, Ventura PJ, Aponte JJ, Kahigwa E, et al. The impact of placental malaria on gestational age and birth weight. J Infect Dis (2000) 181:1740-5. doi:10.1086/315449 increase in parasite densities in the placenta. The decrease in HSPs 70, 60, and 25 levels seems to be responsible for massive cell death in the placenta of $P$. berghei-infected mice and suggest the inefficiency of HSP 90 alone to repair the cell damage $(56,86)$. This study demonstrated that HSPs and cell damage in the malaria-infected placenta are inversely proportion to each other. Therefore, high HSP levels in malaria-infected placenta are important to maintain the normal placental architecture and physiology. Based on the study, therapies can be sought out which can increase the HSP levels in malaria-infected placenta.

\section{CONCLUSION}

Malaria infection during pregnancy is substantial health risk for the pregnant woman as well as to her fetus and newborn. The general immune suppression during pregnancy makes women more susceptible to many infections, including malarial infection especially during first trimester. During pregnancy, cell-mediated immune response is very low that is required to sustain the placenta, a new organ in first pregnancy. However, low cell-mediated immune response in placenta makes it preferred site for the parasite to hide from host immune responses. However, as malarial infection progresses, there is an increase in CMI response resulting in massive recruitment of macrophages to intervillous spaces of placenta and increased concentrations of TNF- $\alpha$ and IFN- $\gamma$ to counteract the parasite iRBC. But this increase in CMI response is deleterious to the placenta which causes oxidative stress and apoptotic cell death in placenta, leading to poor pregnancy outcome, such as abortions, still birth, IUGR, and LBW. Moreover, HSPs that are important for maintenance of normal morphology and physiology of the placenta have been reported in low quantities in malaria-infected placenta. The low HSP levels contribute indirectly to the observed placental pathology by not able to control the cell damage caused by malarial infection. Therefore, placental cell damage and associated consequences in fetus and newborn are accumulative effect of exacerbated inflammation, oxidative stress, apoptosis, and low levels of HSPs in the infected placenta (Figure 1). However, we also need to study other aspects of placental pathologies, especially molecular pathways governing immune responses so that therapies can be designed to modulate the immune response in favor of the host.

\section{AUTHOR CONTRIBUTIONS}

LS: literature survey and wrote the article. GS: edited the article.

4. Watkinson M, Rushton DI. Plasmodial pigmentation of placenta and outcome of pregnancy in West African mothers. Br Med J (1983) 287:251-4 doi:10.1136/bmj.287.6387.251

5. Murphy SC, Breman JG. Gaps in the childhood malaria burden in Africa: cerebral malaria,neurological sequelae, anemia, respiratory distress, hypoglycemia, and complications of pregnancy. Am J Trop Med Hyg (2001) 64:57-67. doi:10.4269/ajtmh.2001.64.57

6. Breman JG, Egan A, Keusch GT. The intolerable burden of malaria: a new look at the numbers. Am J Trop Med Hyg (2001) 64:4-5. doi:10.4269/ajtmh.2001.64.iv 
7. Guyatt HL, Snow RW. Impact of malaria during pregnancy on low birth weight in sub-Saharan Africa. Clin Microbiol Rev (2004) 17:760-9. doi:10.1128/ CMR.17.4.760-769.2004

8. Tarning J. Treatment of malaria in pregnancy. N Engl J Med (2016) 374:981-2. doi:10.1056/NEJMe1601193

9. Poovassery J, Moore JM. Murine malaria infection induces fetal loss associated with accumulation of Plasmodium chabaudi AS-infected erythrocytes in the placenta. Infect Immun (2006) 74:2839-48. doi:10.1128/ IAI.74.5.2839-2848.2006

10. Rogerson SJ, Pollina E, Getachew A, Tadesse E, Lema VM, Molyneux ME. Placental monocyte infiltrates in response to Plasmodium falciparum malaria infection and their association with adverse pregnancy outcomes. Am J Trop Med Hyg (2003) 68:115-9.

11. Rogerson SJ, Brown HC, Pollina E, Abrams ET, Tadesse E, Lema VM, et al. Placental tumor necrosis factor alpha but not gamma interferon is associated with placental malaria and low birth weight in Malawian women. Infect Immun (2003) 71:267-70. doi:10.1128/IAI.71.1.267-270.2003

12. Davison BB, Cogswell FB, Baskin GB, Falkenstein KP, Henson EW, Krogstad DJ. Placental changes associated with fetal outcome in the Plasmodium coatneyi/rhesus monkey model of malaria in pregnancy. Am J Trop Med Hyg (2000) 63:158-73. doi:10.4269/ajtmh.2000.63.158

13. Ismail MR, Ordi J, Menendez C, Ventura PJ, Aponte JJ, Kahigwa E, et al. Placental pathology in malaria: a histological, immunohistochemical and quantitative study. Hum Pathol (2000) 31:85-93. doi:10.1016/S00468177(00)80203-8

14. Saba N, Sultana A, Mahsud I. Outcome and complications of malaria in pregnancy. Gomal J Med Sci (2008) 6:98-101.

15. Neres R, Marinho CRF, Goncalves LA, Catarino MB, Penha-Goncalves C. Pregnancy outcome and placenta pathology in Plasmodium berghei ANKA infected mice reproduce the pathogenesis of severe malaria in pregnant women. PLoS One (2008) 3:e1608. doi:10.1371/journal.pone.0001608

16. Reeder JC. Malaria in pregnancy: getting grip with a sticky problem. PNG Med J (1999) 42:73-6.

17. Desai M, Ter Kuile FO, Nosten F, McGready R, Asamoa K, Brabin B, et al. Epidemiology and burden of malaria in pregnancy. Lancet Infect Dis (2007) 7:93-104. doi:10.1016/S1473-3099(07)70021-X

18. Rogerson SJ, Hviid L, Duffy PE, Leke RF, Taylor DW. Malaria in pregnancy: pathogenesis and immunity. Lancet Infect Dis (2007) 7:105-17. doi:10.1016/ S1473-3099(07)70022-1

19. Rogerson SJ, Mwapasa V, Meshnick SR. Malaria in pregnancy: linking immunity and pathogenesis to prevention. Am J Trop Med Hyg (2007) 77:14-22.

20. Ndam NT, Deloron P. Molecular aspects of Plasmodium falciparum infection during pregnancy. J Biomed Biotech (2007) 168:1-13. doi:10.1155/ $2007 / 43785$

21. Haldara K, Mohandas N. Erythrocyte remodeling by malaria parasites. Curr Opin Hematol (2007) 14:203-9. doi:10.1097/MOH.0b013e3280f31b2d

22. Fried M, Domingo GJ, Mutabingwa TK, Duffy PE. Plasmodium falciparum: chondroitin sulfate $\mathrm{A}$ is the major receptor for adhesion of parasitized erythrocytes in the placenta. Exp Parasitol (2006) 113:36-42. doi:10.1016/j. exppara.2005.12.003

23. Miller LH, Baruch DI, Marsh K, Doumbo OK. The pathogenic basis of malaria. Nature (2002) 415:673-9. doi:10.1038/415673a

24. Achur RN, Valiyaveettil M, Alkhalil A, Ockenhouse CF, Channe Gowda DC. Characterization of proteoglycans of human placenta and identification of unique chondroitin sulfate proteoglycans of the intervillous spaces that mediate the adherence of Plasmodium falciparum infected erythrocytes to the placenta. J Biol Chem (2000) 275:40344-56. doi:10.1074/jbc.M006398200

25. Beeson JG, Brown GV, Molyneux ME, Mhango C, Dzinjalamala F, Rogerson SJ. Plasmodium falciparum isolates from infected pregnant women and children are associated with distinct adhesive and antigenic properties. J Infect Dis (1999) 180:464-72. doi:10.1086/314899

26. Ndam NT, Fievet N, Bertin G, Cottrell G, Gaye A, Deloron P. Variable adhesion abilities and overlapping antigenic properties in placental Plasmodium falciparum isolates. J Infect Dis (2004) 190:2001-9. doi:10.1086/425521

27. Conway DJ. Paths to a malaria vaccine illuminated by parasite genomics. Trends Genet (2015) 31:97-107. doi:10.1016/j.tig.2014.12.005

28. Ndam NT, Salanti A, Bertin G, Dahlbäck M, Fievet N, Turner L, et al. High level of var2csa transcription by Plasmodium falciparum isolated from the placenta. J Infect Dis (2005) 192:331-5. doi:10.1086/430933
29. Ndam NT, Salanti A, Le-Hesran JY, Cottrell G, Fievet N, Turner L, et al. Dynamics of anti-VAR2CSA immunoglobulin G response in a cohort of senegalese pregnant women. J Infect Dis (2006) 193:713-20. doi:10.1086/500146

30. Mackintosh CL, Beeson JG, Marsh K. Clinical features and pathogenesis of severe malaria. Trends Parasitol (2004) 20:597-603. doi:10.1016/j. pt.2004.09.006

31. Maestre A, Carmona-Fonseca J. Immune responses during gestational malaria: a review of the current knowledge and future trend of research. J Infect Dev Ctries (2014) 8:391-402. doi:10.3855/jidc.3777

32. Wochenschr WK. Parasites and pregnancy. Middle Eur JMed (2007) 119:681-4.

33. Davison BB, Kaack MB, Rogers LB, Rasmussen KK, Rasmussen TA, Henson EW, et al. The role of soluble tumor necrosis factor receptor types I and II and tumor necrosis factor-a in malaria during pregnancy. J Infect Dis (2006) 194:123-32. doi:10.1086/504694

34. Othoro C, Moore JM, Wannemuehler KA, Moses S, Lal A, Otieno J, et al. Elevated gamma interferon-producing NK Cells, CD45RO memory-like $\mathrm{T}$ cells, and $\mathrm{CD} 4 \mathrm{~T}$ cells are associated with protection against malaria infection in pregnancy. Infect Immun (2008) 76:1678-85. doi:10.1128/IAI. 01420-07

35. Moore JM, Nahlen BL, Misore A, Lal A, Udhayakumar V. Immunity to placental malaria elevated production of interferon-g by placental blood mononuclear cells is associated with protection in an area with high transmission of malaria. J Infect Dis (1999) 179:1218-25. doi:10.1086/314737

36. Moormann AM, Sullivan AD, Rochford RA, Chensue SW, Bock PJ, Nyirenda T, et al. Malaria and pregnancy: placental cytokine expression and its relationship to intrauterine growth retardation. J Infect Dis (1999) 180:1987-93. doi:10.1086/315135

37. Conroy A, Serghides L, Finney C, Owino SO, Kumar S, Gowda DC, et al. C5a enhances dysregulated inflammatory and angiogenic responses to malaria in vitro: potential implications for placental malaria. PLoS One (2009) 4:e4953. doi:10.1371/journal.pone.0004953

38. Miu J, Mitchell AJ, Ball HJ, Hunt NH. Chemokines and malaria infection. Curr Immunol Rev (2006) 2:331-44. doi:10.2174/1573395510602040331

39. Megnekoua R, Tenoua S, Bigogab JD, Djontua JC, Medoua FM, Lissom A. Placental malaria and modulation of immune and hormonalresponses in Cameroonian women. Acta Trop (2015) 147:23-30. doi:10.1016/j.actatropica. 2015.04.001

40. Avril M, Gamain B, LePolard CN, Viaud N, Scherf A, Gysin J. Characterization of anti-var2CSA-PfEMP1 cytoadhesion inhibitory mouse monoclonal antibodies. Microbes Infect (2006) 8:2863-71. doi:10.1016/j.micinf.2006. 09.005

41. Duffy PE, Fried M. Antibodies that inhibit Plasmodium falciparum adhesion to chondroitin sulfate A are associated with increased birth weight and the gestational age of newborns. Infect Immun (2003) 71:6620-3. doi:10.1128/ IAI.71.11.6620-6623.2003

42. Staalsoe T, Shulman CE, Bulmer JN, Kawuondo K, Marsh K, Hviid L. Variant surface antigen-specific IgG and protection against clinical consequences of pregnancyassociated Plasmodium falciparum malaria. Lancet (2004) 363:257-338. doi:10.1016/S0140-6736(03)15386-X

43. Salanti A, Dahlbäck M, Turner L, Nielsen MA, Barfod L, Magistrado P, et al. Evidence for the involvement of VAR2CSA in pregnancy-associated malaria. J Exp Med (2004) 200:1197-203. doi:10.1084/jem.20041579

44. Hubel CA. Oxidative stress in the pathogenesis of preeclampsia. Proc Soc Exp Biol Med (1999) 222:222-35. doi:10.1046/j.1525-1373.1999.d01-139.x

45. Gutteridge JM. Lipid peroxidation and antioxidants as biomarkers of tissue damage. Clin Chem (1995) 41:1819-28.

46. Jauniaux E, Poston L, Burton GJ. Placental-related diseases of pregnancy: involvement of oxidative stress and implications in human evolution. Hum Reprod Update (2006) 12:747-55. doi:10.1093/humupd/dml016

47. Sharma JB, Sharma A, Bahadur A, Vimala N, Satyam A, Mittal S. Oxidative stress markers and antioxidant levels in normal pregnancy and pre-eclampsia. Int J Gynaecol Obstet (2006) 94:23-7. doi:10.1016/j.ijgo.2006.03.025

48. Agarwal A, Gupta S, Sharma RK. Role of oxidative stress in female reproduction. Reprod Biol Endocrinol (2005) 3:1-21. doi:10.1186/1477-7827-3-28

49. Jayshree RS, Ganguli NK, Dubey ML, Mohan K, Mahajan RC. Generation of reactive oxygen species by blood monocytes during acute $P$. knowlesi infection in rhesus monkeys. APMIS (1993) 101:762-6. doi:10.1111/j. 1699-0463.1993.tb00177.x 
50. Kharazmi A, Jepsen S, Andersen BJ. Generation of reactive oxygen radicals by human phagocytic cells activated by P. falciparum. Scand J Immunol (1987) 25:335341. doi:10.1111/j.1365-3083.1987.tb02198.x

51. Das BS, Nanda NK. Evidence for erythrocyte lipid peroxidation in acute falciparum malaria. Trans R Soc Trop Med Hyg (1999) 93:58-62. doi:10.1016/ S0035-9203(99)90180-3

52. Clark IA, Hunt NH. Evidence for reactive oxygen intermediates causing hemolysis and parasite death in malaria. Infect Immun (1983) 39:1-6.

53. Clark IA, Hunt NH, Cowden WB. Oxygen-derived free radicals in the pathogenesis of parasitic disease. Adv Parasitol (1986) 25:1-45. doi:10.1016/ S0065-308X(08)60341-3

54. Ockenhouse CF, Shear HL. Oxidative killing of the intra erythrocytic malaria parasite P. yoelii by activated macrophages. J Immunol (1984) 132:424-31.

55. Wozencraft AO, Dockrell HM, Taverne J, Targett GAT, Playfair JHL. Killing of human malaria parasite by macrophage secretory products. Infect Immun (1984) 43:664-9.

56. Sharma L, Kaur J, Shukla G. Role of oxidative stress and apoptosis in the placental pathology of Plasmodium berghei infected mice. PLoS One (2012) 7:e32694. doi:10.1371/journal.pone.0032694

57. Sharma L, Kaur J, Rishi P, Shukla G. Plasmodium berghei: influence of infection on the oxidant and antioxidants levels in pregnant BALB/c mice. Exp Parasitol (2012) 131:215-22. doi:10.1016/j.exppara.2012.04.005

58. Kulkarni AG, Suryakar AN, Sardeshmukh AS, Rathi DB. Studies on biochemical changes with special reference to oxidant and antioxidants in malaria patients. Indian J Clin Biochem (2003) 18:136-49. doi:10.1007/ BF02867380

59. Pabon A, Carmona J, Burgos LC, Blair S. Oxidative stress in patients with non-complicated malaria. Clin Biochem (2003) 36:71-8. doi:10.1016/ S0009-9120(02)00423-X

60. Akanbi OL. Effect of malaria infection on oxidative stress and lipid profile in pregnant women. J Med Med Sci (2013) 4(3):128-33.

61. Fried M, Muga RO, Misore AO, Duffy PE. Malaria elicits type 1 cytokines in the human placenta: IFN-g and TNF-a associated with pregnancy outcomes. J Immunol (1998) 160:2523-30.

62. Porta J, Carota A, Pizzolato GP, Wildi E, Widmer MC, Margairaz C, et al. Immunopathological changes in human cerebral malaria. Clin Neuropathol (1993) 12:142-6.

63. Curfs JHAJ, Schetters TPM, Hermsen CC, Jerusalem CR, van Zon AA, Eling WMC. Immunological aspects of cerebral lesions in murine malaria. Clin Exp Immunol (1989) 75:136-40.

64. Thompson CB. Apoptosis in the pathogenesis and treatment of disease. Science (1995) 267:1456-62. doi:10.1126/science.7878464

65. Onishi Y, Kizaki H. Apoptosis and diseases. Hum Cell (1994) 7:27-32.

66. Shimizu S, Narita M, Tsujimoto Y. Bcl-2 family proteins regulate the release of apoptogenic cytochrome $\mathrm{c}$ by the mitochondrial channel VDAC. Nature (1999) 399:483-7. doi:10.1038/20959

67. Ameisen JC. From cell activation to cell depletion. The programmed cell death hypothesis of AIDS pathogenesis. Adv Exp Med Biol (1995) 374:139-63. doi:10.1007/978-1-4615-1995-9_13

68. Gschwind M, Huber G. Apoptotic cell death induced by beta-amyloid 1-42 peptide is cell type dependent. JNeurochem (1995) 65:292-300. doi:10.1046/j.1471-4159.1995.65010292.x

69. Sharma L, Shukla G. Treatment of pregnant BALB/c mice with sulphadoxine pyrimethamine or chloroquine abrogates Plasmodium berghei induced placental pathology. Parasitol Int (2014) 63(1):49-56. doi:10.1016/j.parint. 2013.08.016

70. Welch WJ. Mammalian stress response: cell physiology, structure/function of stress protein and implication for medicine and diseases. Physiol Rev (1992) 27:1063-81.

71. Voss AK, Thomas T, Gruss P. Mice lacking HSP90b fail to develop a placental labyrinth. Development (2000) 12:1-11.
72. Shah M, Stanek J, Handwerger S. Differential localization of heat shock proteins 90, 70, 60 and 27 in human deciduas and placenta during pregnancy. Histochem J (1998) 30:509-18. doi:10.1023/A:1003259907014

73. Neuer A, Mele C, Liu HC, Rosenwaks A, Witkin SS. Monoclonal antibodies to mammalian heat shock proteins impair mouse embryo development in vitro. Hum Rep (1998) 13:987-90. doi:10.1093/humrep/13.4.987

74. Christians ES, Zhou Q, Renard J, Benjamin IJ. Heat shock proteins in mammalian development. Semin Cell Dev Biol (2003) 14:283-90. doi:10.1016/j. semcdb.2003.09.021

75. Loones MT, Rallu M, Mezger V, Morange M. HSP gene expression and HSF2 in mouse development. Cell Mol Life Sci (1997) 53:179-90. doi:10.1007/ PL00000590

76. Bensuade O, Babinet C, Morange M, Jacob F. Heat shock proteins, first major products of zygotic gene activity in the mouse embryo. Nature (1983) 305:331-3. doi:10.1038/305331a0

77. Schlesinger MJ. Heat shock proteins: mini review. JBiol Chem (1990) 265:12111-4.

78. Benjamin IJ, McMillan DR. Stress (heat shock) proteins: molecular chaperones in cardiovascular biology and disease. Circ Res (1998) 83:117-32. doi:10.1161/01.RES.83.2.117

79. Shan YX, Liu TJ, Su HF, Samsamshariat A, Mestril R, Wang PH. Hsp10 and Hsp60 modulate Bcl-2 family and mitochondria apoptosis signaling induced by doxorubicin in cardiac muscle cells. J Mol Cell Cardiol (2003) 35:1135-43. doi:10.1016/S0022-2828(03)00229-3

80. Pandey P, Saleh A, Nakazawa A, Kumar S, Srinivasula SM, Kumar V, et al. Negative regulation of cytochrome c-mediated oligomerization of Apaf-1 and activation of procaspase-9 by heat shock protein 90. EMBO J (2000) 19:4310-22. doi:10.1093/emboj/19.16.4310

81. Mosser DD, Caron AW, Bourget L, Denis-Larose C, Massie B. Role of the human heat shock protein hsp70 in protection against stress induced apoptosis. Mol Cell Biol (1997) 17:5317-27. doi:10.1128/MCB.17.9.5317

82. Ravagnan L, Gurbuxani S, Susin SA, Maisse C, Daugas E, Zamzami N, et al. Heat-shock protein 70 antagonizes apoptosis-inducing factor. Nat Cell Biol (2001) 3:839-43. doi:10.1038/ncb0901-839

83. Jaattela M, Wissing D, Kokholm K, Kallunki T, Egeblad M. Hsp70 exert its anti-apoptotic function downstream of caspase-3 like proteases. $E M B O \mathrm{~J}$ (1998) 17:6124-34. doi:10.1093/emboj/17.21.6124

84. Li L, Xiao-jin Z, Su-rong J, Zheng-nian D, Guo-xian D, Jun H, et al. Heat shock protein 27 regulates oxidative stress-induced apoptosis in cardiomyocytes: mechanisms via reactive oxygen species generation and Akt activation. Chin Med J (2007) 120:2271-7.

85. Lee YJ, Lee DH, Cho CK, Chung HY, Bae S, Jhon GJ, et al. HSP25 inhibits radiation-induced apoptosis through reduction of $\mathrm{PKCd}$-mediated ROS production. Oncogene (2005) 24:3715-25. doi:10.1038/sj.onc.1208440

86. Sharma L, Kaur J, Shukla G. Expression of heat shock protein 90, 70, 60 and 25 in the placenta of Plasmodium berghei infected BALB/c mice. Asian Pac J Trop Dis (2014) 3:930-2. doi:10.1016/S2222-1808(14)60487-4

Conflict of Interest Statement: The authors declare that the research was conducted in the absence of any commercial or financial relationships that could be construed as a potential conflict of interest.

The handling editor and the reviewer ML declared their shared affiliation, and the handling editor states that the process nevertheless met the standards of a fair and objective review.

Copyright (c) 2017 Sharma and Shukla. This is an open-access article distributed under the terms of the Creative Commons Attribution License (CC BY). The use, distribution or reproduction in other forums is permitted, provided the original author(s) or licensor are credited and that the original publication in this journal is cited, in accordance with accepted academic practice. No use, distribution or reproduction is permitted which does not comply with these terms. 